\title{
Range of Separation of Potential Tool for Bioseparation, Microchip Electrophoresis System, for DNA Polymorphisms on the Human Y-Chromosome
}

\author{
Mohammad JABASINI, ${ }^{* 1 \dagger}$ Feng XU, ${ }^{* 1, * 3}$ Fuquan DANG, ${ }^{* 1}$ Toshikatsu ShINKA, ${ }^{* 2}$ \\ Yutaka NAKAHORI, ${ }^{* 2}$ and Yoshinobu BABA $* 1, * 4$
}

*1 Department of Medicinal Chemistry, Faculty of Pharmaceutical Sciences, The University of Tokushima, CREST, Japan Science and Technology Corporation (JST), Tokushima 770-8505, Japan

*2 Department of Human Genetics Public Health, School of Medicine, The University of Tokushima, Tokushima 770-8505, Japan

*3 Life Science Department, Shimadzu Corporation, 1 Nishinokyo-Kuwabara-cho, Kyoto 604-8511, Japan

*4 Single-Molecule Bioanalysis Laboratory, National Institute of Advanced Industrial Science and Technology (AIST), Hayashi-cho 2217-14, Takamatsu 761-0395, Japan

\begin{abstract}
For the requirement of a high, fast and sufficient technology to suit the needs of 21 st century biotechnology, the separation range of a microchip electrophoresis system was studied. Two DNA fragments on the human Y-chromosome, SY594 (82 bp) and 12f2 (88 bp), were successfully separated with a reproducibility of $1.9 \%$ and an accuracy of $2.8 \%$. Then, a mixture of 10 DNA markers ranging from $61 \mathrm{bp}$ to $189 \mathrm{bp}$ was successfully separated with high resolution. All of these results demonstrate the superiority of microchip electrophoresis as a tool for 21 st century bioseparation.
\end{abstract}

(Received October 1, 2002; Accepted November 20, 2002)

\section{Introduction}

In his review article published in Science (March, 2000), Francis Collins, the head of National Human Genome Research Institute (NHGRI), said that although it took 4 years to obtain the first billion out of 3 billion bases in the human genome, it took only 4 months to obtain the second billion. ${ }^{1}$ At that time, because $10 \%$ of the genome was being added to GenBank each month, ${ }^{2}$ by early 2001 the human genome was almost completed owing to sufficient technology, which increased its rapid sequencing. The Human Genome Project (HGP) is presently moving quickly to the post-genome era, which will stimulate investigations of single nucleotide polymorphism (SNP), mutation analysis and proteome analysis. ${ }^{3}$ This will lead to gene therapy and DNA diagnosis of human diseases, which will result in a new class of drugs. ${ }^{4}$

This significant progress is partly due to a huge leap in electrophoresis technology. Capillary electrophoresis has facilitated applications of these technologies to the analysis of DNA with high efficiency, high resolution and a short analysis time. In the post-genome era, the further development of analytical technology is highly required for high-throughput screening of disease-causing genes and the high-speed analysis of genetic polymorphisms. Microchip capillary electrophoresis holds great promise for this biocentury owing to its highthroughput DNA analysis. Significant innovations are expected due to widespread applications of micromachining to chemistry and biotechnology. ${ }^{5}$ In the present work, analyses of two DNA

\footnotetext{
$\doteqdot$ To whom correspondence should be addressed.

E-mail: c400141005@stud.tokushima-u.ac.jp
}

polymorphisms on human Y-chromosome, SY 594 and 12f2, were carried out using an Agilent 2100 Bioanalyzer, in order to examine the minimum base-pair difference that can be separated. More further, we examined the maximum number of polymorphisms that could be separated. Ten DNA markers located on the human Y-chromosome were successfully separated.

\section{Experimental}

Michrochip electrophoresis system: Agilent Bioanalyzer (Agilent Technologies, Waldbronn, Germany), which has epifluorescent detection with a semi conductor laser that emits at $630 \mathrm{~nm}$.

The chips: Consist of 12 sample wells with 3 gel-dye mix wells and one for the external marker. It was made of soda lime glass, depth of $10 \mu \mathrm{m}$, the width of $50 \mu \mathrm{m}$ and effective separation length of $15 \mathrm{~mm}$.

Assay kits: DNA 500 and DNA 7500 assay kits from Agilent technologies Including the dye, gel matrix, DNA marker, and DNA ladder solution.

Human Y-chromosome DNAs: Obtained from Prof. Nakahori Lab., School of Medicine, The University of Tokushima. They have been prepared according to the methods described in literature. ${ }^{6,7}$

\section{Results and Discussion}

In previous work, we studied the accuracy and reproducibility of an Agilent 2100 Bioanalyzer on some polymorphisms located on the human Y-chromosome. ${ }^{3}$ Indeed, the human Ychromosome has unique characteristics in genetics because it is 
Table 1 Validation of ten DNA markers on the human Ychromosome

\begin{tabular}{llrll}
\hline \multicolumn{1}{c}{$\begin{array}{c}\text { Y-Chromosome } \\
\text { marker }\end{array}$} & $\begin{array}{c}\text { Gene or } \\
\text { locus }\end{array}$ & Avg. (bp) & RSD, \% & RE, \% \\
\hline SY 619 (61 bp) & DBY & 63 & 1.2 & 2.2 \\
SY 592 (69 bp) & UTY & 68 & 0.72 & 0.5 \\
SY 595 (81 bp) & BPY1 & 81 & 0.64 & 0.2 \\
12f2 (88 bp) & AFZa & 87 & 0.69 & 1.2 \\
SY 593 (102 bp) & TB4Y & 103 & 0.44 & 0.9 \\
12f2 inner marker (112 bp) & AFZa & 111 & 0.46 & 0.9 \\
SY 202 (121 bp) & AFZc & 119 & 0.80 & 1.8 \\
YAP (150 bp) & DYS287 & 145 & 0.6 & 3.6 \\
SY 90 (176 bp) & KALY & 177 & 0.5 & 0.7 \\
SY200 (189 bp) & TSPY & 188 & 0.47 & 0.5 \\
\hline
\end{tabular}

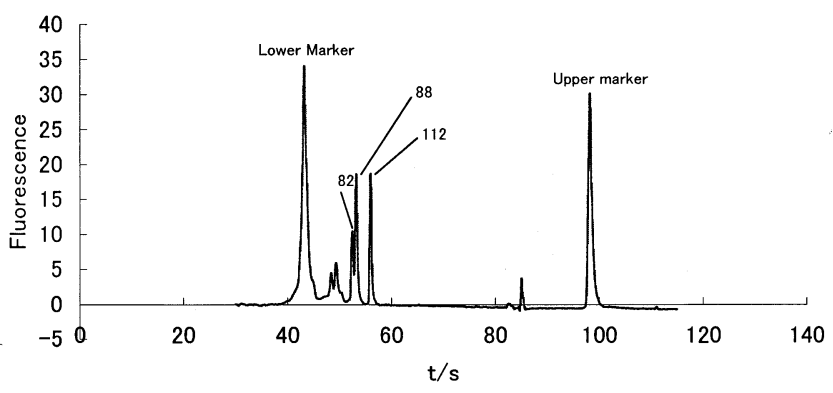

Fig. 1 Separation of SY $594(82 \mathrm{bp})$ and $12 \mathrm{f} 2(88 \mathrm{bp})$. These peaks are in the order: the lower marker, SY 594 (82 bp), $12 \mathrm{f} 2$ (88 bp), inner marker added to $12 \mathrm{f} 2$ (112 bp), the upper marker.

a single haploid unit in the human genome that is passed from father to son. We thus chose several markers located on this chromosome to study (Table 1), which are related to spermatogenic failure. In this study, in order to examine the minimum base-pair size difference that the Agilent 2100 Bioanalyzer can separate, two DNA polymorphisms, SY594 (82 bp) and $12 \mathrm{f} 2(88 \mathrm{bp})$, from the human $\mathrm{Y}$-chromosome were analyzed. By using the DNA 500 Assay Kit, Agilent 2100 Bioanalyzer showed sufficient ability to separate these two polymorphisms (Fig. 1). The separation was repeated 30 times on 3 chips. The reproducibility (RSD\%) was less than $1.9 \%$, while the accuracy (RE\%) was $2.8 \%$.

In order to confirm these results, another range of sizes $(60$ $70 \mathrm{bp}$ ) was chosen to study. Two markers one the human Ychromosome, SY638 (64 bp) and SY592 (69 bp), were successfully separated (Fig. 2). Narrower two size difference between two DNA fragments, SY 603 (84 bp) and 12f2 (88 bp), examined using the Bioanalyzer, they could not be separated, because they showed one overlap peak (data not shown). From this result we can say that the minimum size different that can be separated by the Agilent 2100 Bioanalyzer is 6 bp difference. This separation is reproducible with high resolution. In order to examine the maximum DNA fragments that a microchip electrophoresis system can separate, a mixture of ten DNA markers on the human Y-chromosome related to spermatogenic failure were analyzed. These ten markers were successfully separated within $80 \mathrm{~s}$ (Fig. 3). As shown in Table 1, the reproducibility (RSD\%) for the ten markers was less than $1.2 \%$, while the accuracy (RE\%) was less than $3.6 \%,(n=30)$. Taking all of these data together, we can conclude that microchip electrophoresis shows its superiority in the analysis of genome polymorphisms, with a minimum base pair difference of $6 \mathrm{bp}$,

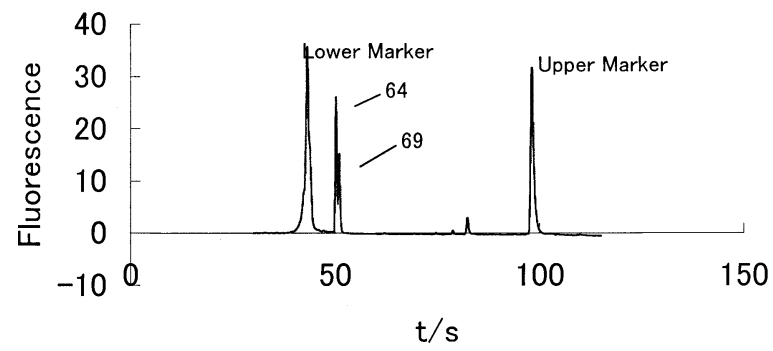

Fig. 2 Separation of SY 638 (64 bp) and SY 592 (69 bp). These peaks are in the order: the lower marker, SY 638 (64 bp), SY 592 (69 bp), the upper marker.

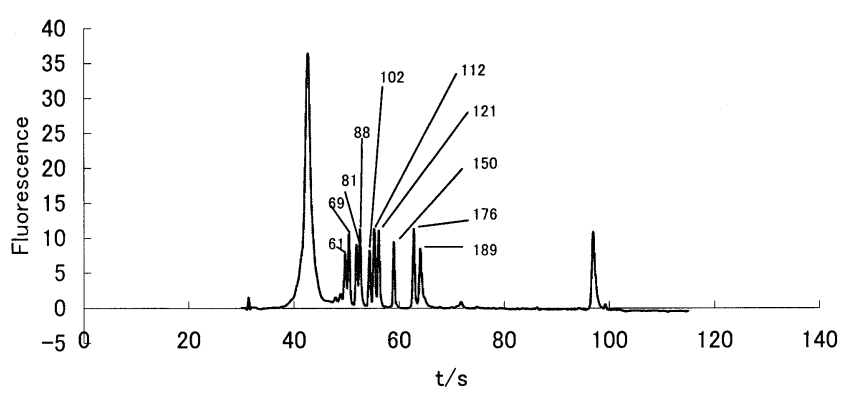

Fig. 3 Separation of ten DNA markers on the human Ychromosome. These peaks are in the order: the lower marker, SY 610 (61bp), SY 592 (69 bp), SY 595 (81 bp), 12f2 (88 bp), SY 593 (102 bp), $12 \mathrm{f} 2$ inner marker (112 bp), SY 202 (121 bp), YAP (150 bp), SY 90 (176 bp), SY 200 (189 bp), the upper marker.

and a maximum polymorphism number, of 10 DNA markers, ranging from $61 \mathrm{bp}$ to $189 \mathrm{bp}$, with the advantages of high resolution, high speed, good reproducibility and accuracy. All of these advantages put microchip electrophoresis among the tops of the 21st century bioseparation technologies.

\section{Acknowledgements}

This work was partially supported by the CREST program of Japan Science and Technology Corporation (JST), a grant from the New Energy and Industrial Technology Development Organization (NEDO) of the Ministry of Economy, Trade and Industry, Japan, a Grant-in-Aid for Scientific Research from the Ministry of Health and Welfare, Japan. The authors would like to thank K. Tsuji, A. Endo and Y. Unemi for their excellent technical support.

\section{References}

1. E. Marshall, Science, 2000, 287, 2396.

2. L. Mitnik, M. Novotny, C. Felten, S. Buonocore, L. Koutny, and D. Schmalzing, Electrophoresis, 2001, 22, 4104.

3. M. Jabasini, L. Zhang, F. Dang, F. Xu, M. Almofti, A. Ewis, J. Lee, Y. Nakahori, and Y. Baba, Electrophoresis, 2002, 23, 1537.

4. M. Ueda, O. Tabata, and Y. Baba, T.IEE Japan, 1999, Vol.112 E, No. 10.

5. M. Chiari, Electrophoresis, 2002, 23, 536.

6. M. F. Hammer, Mol. Biol. Evol., 1994, 11, 749.

7. P. Blanco, M. Shlumuskova, C. A. Sargent, M. A. Jobling, N. Affara, and M. E. Hurles, J. Med. Genet., 2000, 37, 752. 